\title{
Reducing Delay Time at Signal Controlled Junction with the Help of Actuated Control
}

\author{
L'ubomír Černický'*, Jana Kupčuljaková', Jozef Palo', Alica Kalašová' \\ 1 University of Žilina, Faculty of Operation and Economics of Transport and Communications, Department of \\ Road and Urban Transport, Univerzitná 1, 01026 Žilina, Slovak Republic \\ * Corresponding author's e-mail: lubomir.cernicky@fpedas.uniza.sk
}

\begin{abstract}
Nearly every town faces the traffic problem caused by the continuous increase of the traffic volume. Traffic collapses, congestions, accidents and a further negative impact on the environment are gradually becoming a common part of our lives. Junctions are the most critical points of the road network, which usually determine the capacity of the roads. Therefore, proper traffic organization at junctions is a necessity. This paper analyses the actuated control in comparison to the fixed control at a signal-controlled junction. It also includes a case study of one problematic junction in this paper. With the help of microscopic simulation in Aimsun, 2 solutions for this problematic junction were assessed, one of which is fixed control and other is actuated control. Actuated traffic control gives better results than fixed control.
\end{abstract}

Keywords: actuated control, microscopic simulation, delay time, Aimsun, fixed control, traffic lights.

\section{INTRODUCTION}

In recent years, there has been a large increase in individual transportation due to the rising living standard and systematic economic preference of individual car transportation. Hence, the road network ceases to satisfy in terms of capacity and permeability. Traffic collapses, congestions, accidents and a further negative impact on the environment are gradually becoming a common part of our lives $[1,2]$. In smaller towns (up to 100000 of inhabitants) poor traffic conditions can often be solved with simple solutions such as reorganisation of traffic, building roundabouts, traffic lights etc. Every kind of solution has its advantages and disadvantages, e.g. Gavulova [3] evaluated the capacity of roundabouts in Slovakia, Lizbetin [4] proposed roundabouts in selected area in order to optimize transport and logistics services. Mateen [5] proposed architecture of Agent/Based Autonomous Controller, whereas Culik [6] compared various types of traffic organizations at a selected junction.

Traffic responsive control began to evolve since the mid-1980s. Likewise, almost every new or repaired signal-controlled junction is designed with traffic responsive control. These junctions are able to adapt the lengths and order of the green phase to the current traffic situation and thus can speed up crossing the junction, especially when the traffic load changes [7].

Pribyl [7] compared static control, actuated control and fuzzy control. Their results showed that the fuzzy control and actuated control are convenient for low traffic at the junction. Fuzzy control gave $20 \%$ better results and actuated control gave $16 \%$ better results compared to static traffic control. If the traffic increases, fuzzy control becomes less and less convenient. Moreover, in the high traffic, the fuzzy control is even worse than static control. Actuated traffic control always gave better results than static control, but the higher the traffic volume was simulated, the smaller the difference between static control and actuated control was obtained [7].

Moreover, study [8] concluded that "Adaptive Traffic Control System increases the traffic fluency when compared with other static traffic control systems". Very similar results were reported 
in [9], which says that actuated traffic controllers perform better than static ones. It is important to notice, that the public transport vehicles are also affected by many external factors including traffic volume, organization and infrastructure [10]. As traffic organisation has an impact on the fuel consumption, in this way actuated traffic control can decrease the emission of greenhouse gases. Another way of decreasing these emissions is described in $[11,12]$. Moreover, actuated control with the combination of video systems could lead to increase of traffic safety [13].

\section{ACTUATED TRAFFIC CONTROL AS AN EFFECTIVE TOOL FOR DECREASING DELAY TIMES IN THE SLOVAK CITIES}

If the largest Slovak cities, i.e. Bratislava and Košice are not considered, the number of the signal-controlled junctions is relatively low, e.g. there are only 25 signal-controlled junctions in Prešov (88,000 of inhabitants), or 12 signal-controlled junctions in Žilina (80,000 of inhabitants) etc. Many times, these junctions are controlled separately or only in coordination with each other. The traffic lights have fixed or actuated control. Few years ago, no other "higher level" of control was used. This situation has been changed to the certain extent at presentm as towns try to prioritize the public transport. For instance, there is a public transport priority system at the 9 signalcontrolled junctions in Žilina; Prešov is also planning to implement such kind of traffic light control at its junctions. It is only the question of time, when other Slovak towns will also implement this "higher level" of control in their territory. Till that time, fixed and actuated traffic control will be the most common solutions in Slovakia. More and more towns want to have signal-controlled junctions with actuated control so it can be assumed that the ratio between fixed and actuated control will change in favour of the latter.

\section{ASSESSING THE CAPACITY OF JUNCTION WITH ACTUATED TRAFFIC CONTROL IN THE SLOVAK REPUBLIC}

Traffic capacity assessment in the Slovak Republic is carried out according to the technical regulations or with the help of microscopic simulations. Regarding the signal-controlled junction, technical regulations can assess only static traffic control. There is no process, no formula for accessing actuated traffic control in this technical regulation [14].

In the Slovak Republic Traffic assessment with the help of microscopic simulation is usually carried out by means of VISSIM software. The advantage of microscopic simulation is in its clarity for all stakeholders, versatility, ability to implement into the calculation of the influence of the surroundings, etc.

Although microscopic simulation in VISSIM enables to assess the junctions with actuated traffic control, this option is not very often used in the Slovak Republic. The experience from the capital indicates that traffic capacity assessment is carried out for the static traffic control. It is always assumed that actuated traffic control can only increase permeability of the junction compared to static traffic control. Thus, if the junction with the static control is capable of managing the expected traffic volume, then the same junction but with the actuated control is also capable of managing the same traffic volume [15].

\section{IMPROVING TRAFFIC WITH THE HELP OF ACTUATED CONTROL - CASE STUDY}

One of the problematic junctions in the Slovak republic is located in the city of Martin. The junction consists of the road I/65 and III/2144 and is situated about $4 \mathrm{~km}$ from the Bystrička village (see Fig. 1 on left). Most of the active working population commute to work to Martin. The junction entrance from Bystrička- left turn (from D to B in fig. 1) is very hard to drive through and also there are long delays on the entrance to the village, especially in the morning peak hour [1]. The situation on the junction is very bad and still not solved because the junction consists of the roads that do not belong to Martin, although they are on the territory of Martin. This kind of problem is described e.g. in [16]. At present, Martin intends to build traffic lights at this junction. Martin prefers building traffic lights with actuated control to fixed control.

In order to assume the future situation at the junction, a microscopic simulation in Aimsun was carried out. Three variants were investigated: 1) Simulation of the current traffic situation at this junction.

2) Simulation of the traffic lights with fixed control.

3) Simulation of the traffic lights with actuated control. 

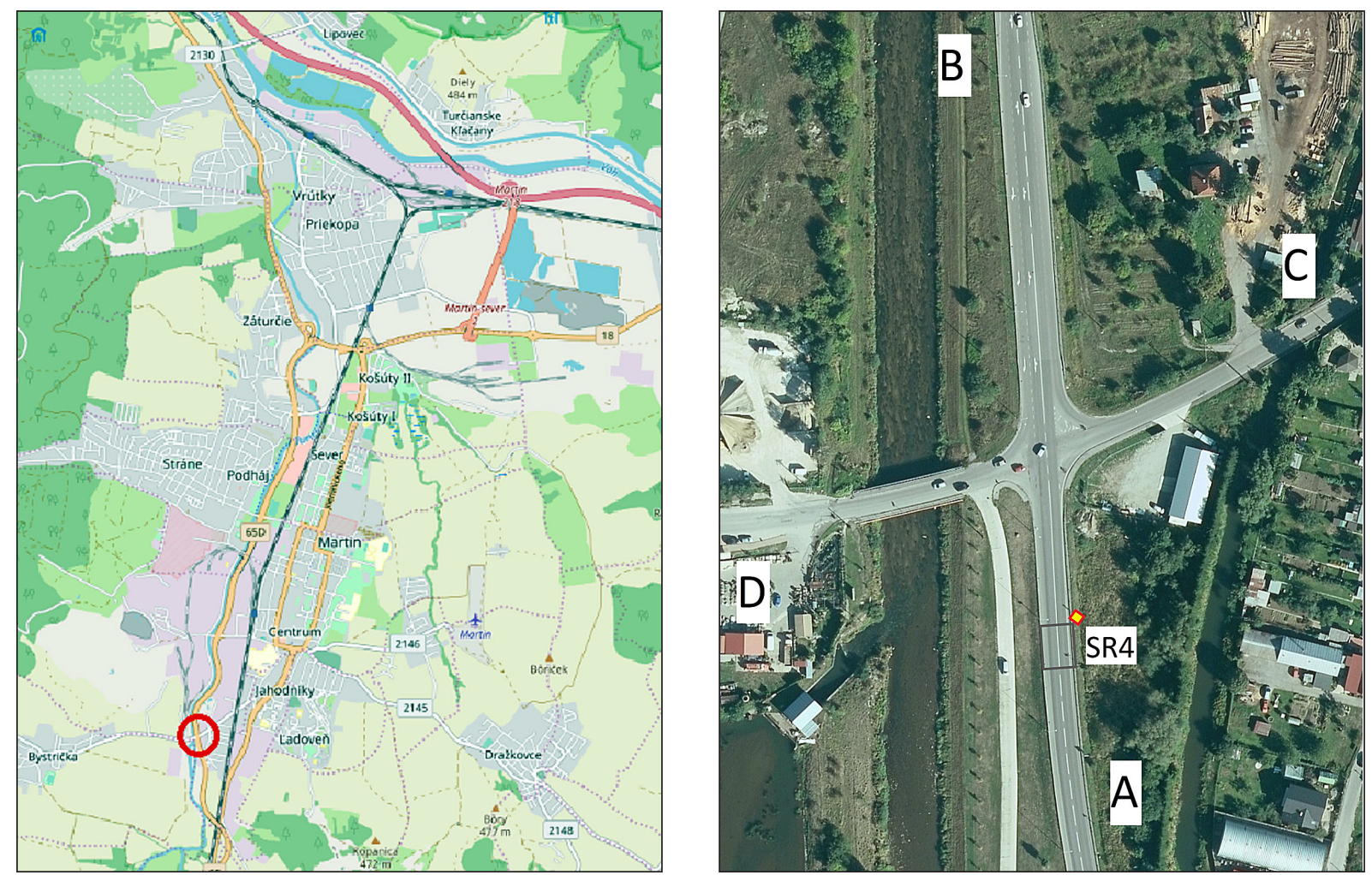

Fig. 1. Localisation and detailed view at the junction

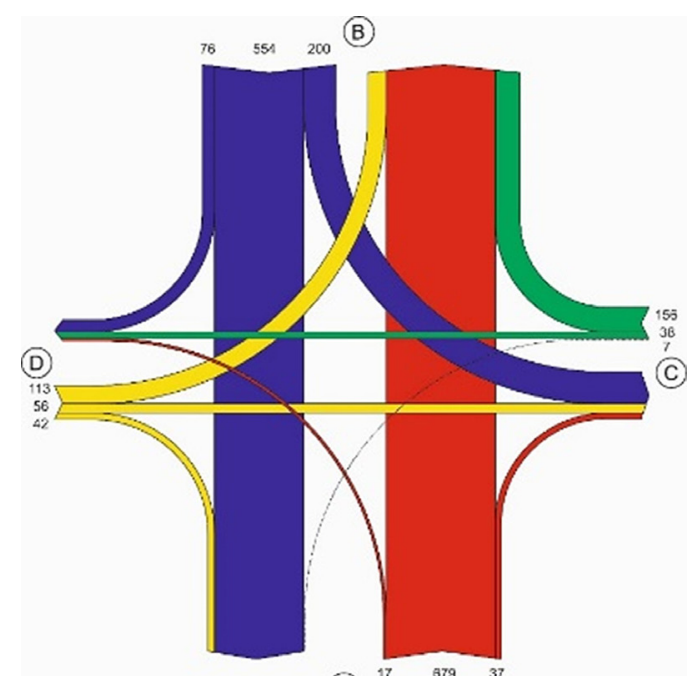

(A)
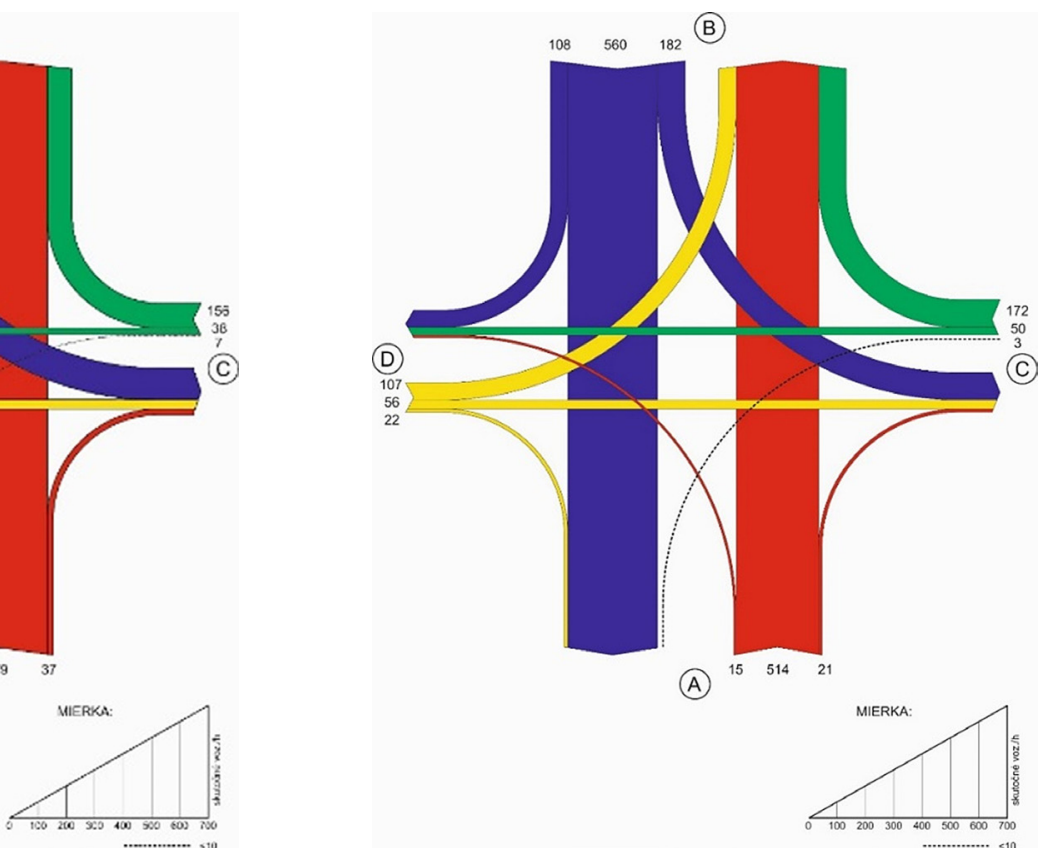

(A)

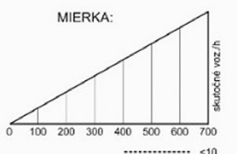

Fig. 2. Traffic volume at the junction (morning peak on the left, afternoon peak on the right)

The input data for the simulation were traffic volumes at the sections, turnings of vehicles at the junction, public transport lines, characteristics of individual vehicles, calculated signal plans of the junctions and designed adaptive control.
The traffic volume was obtained from the traffic survey of the University of Žilina on $17^{\text {th }}$ September 2019 (see Fig. 2). The survey was carried out according to the technical conditions 102 [14]. It was carried out as manual traffic count 


\section{Number of vehicles in 5 minute intervals}

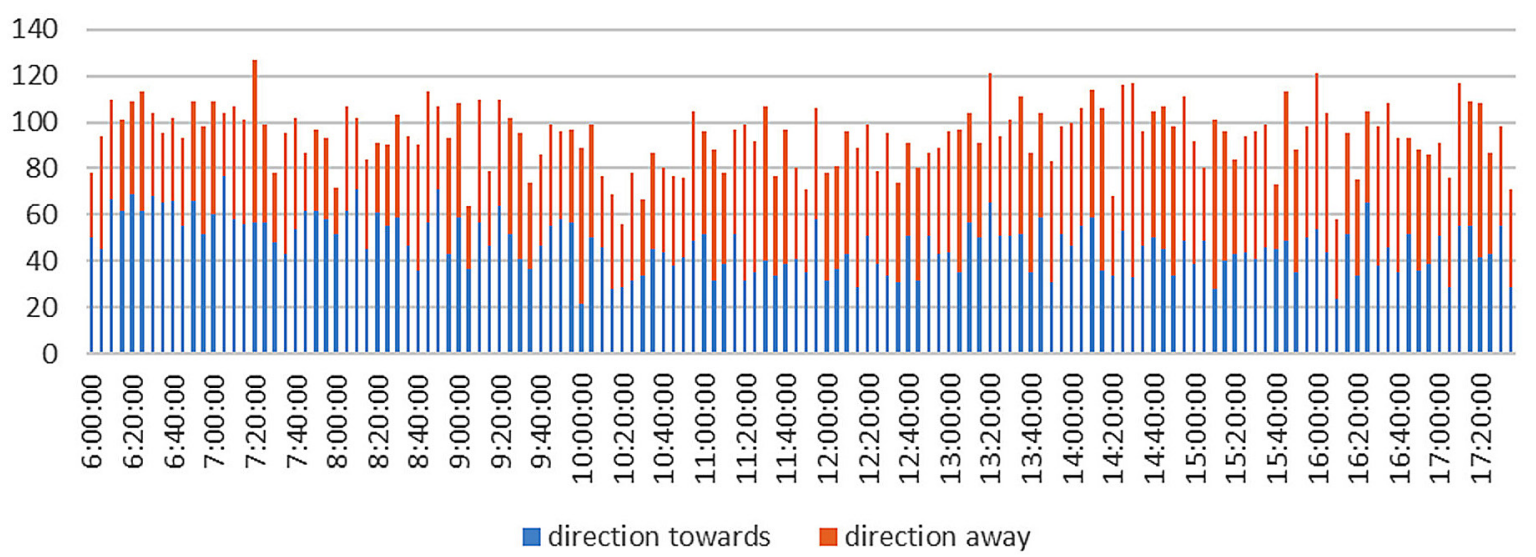

Fig. 3. Number of vehicles in 5 minute intervals counted by Sierzega SR4

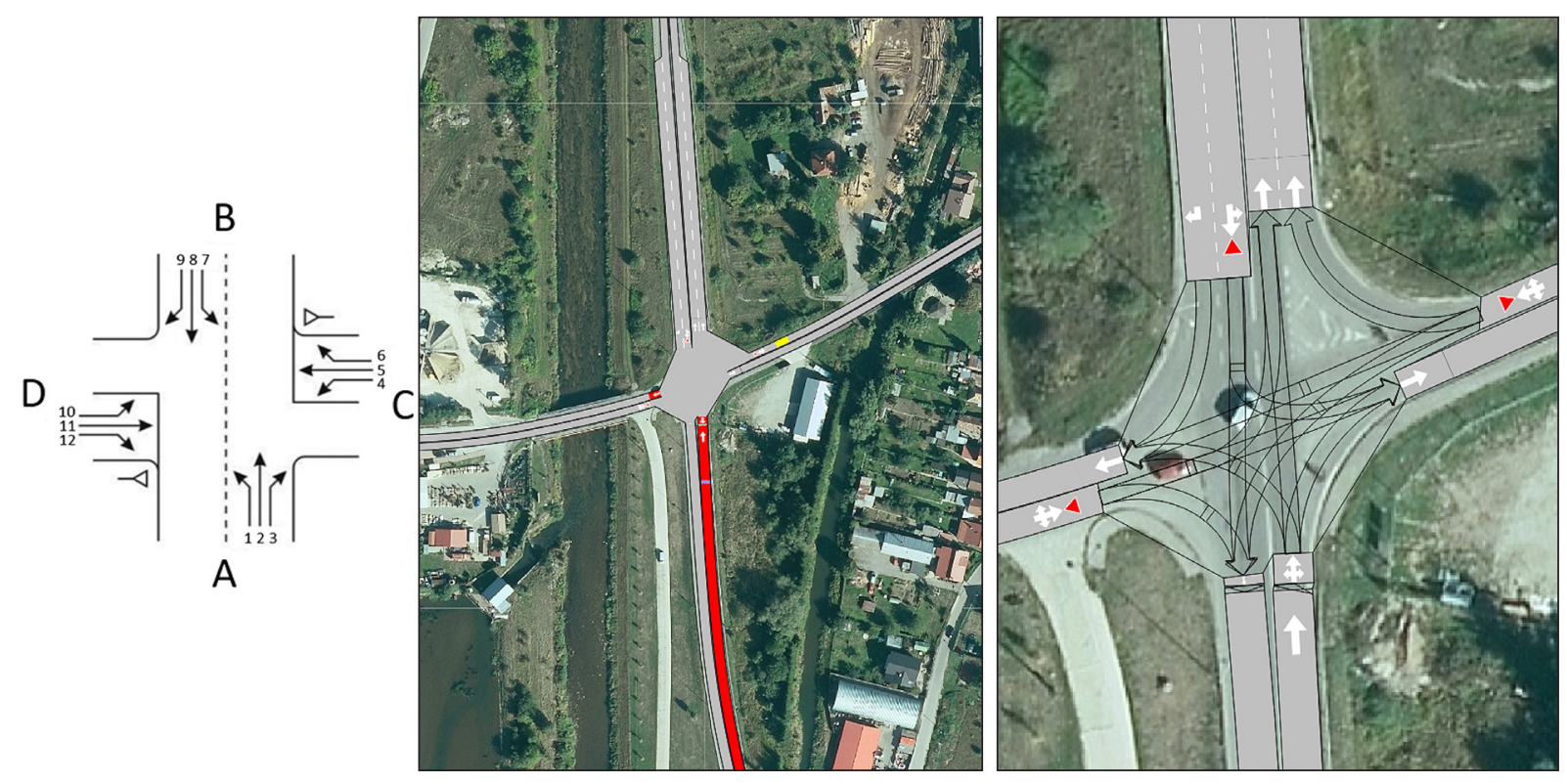

Fig. 4. Model of the current traffic situation (left: traffic flows according TP102, middle: subpath no. 1, right: detailed view of the junction)

with the combination of automated traffic count with the help of the Sierzega SR4 device. Sierzega SR4 was placed on the main road at the entrance A (see Fig. 1 on right).

The morning peak was between $7: 15$ and $8: 15$, when 1975 vehicles entered the junction, as it can be seen in Fig. 2 on the left. The afternoon peak was between 15:15 and 16:16, when 1810 vehicles entered the junction, as shown in Fig. 2 on the right. As it can be seen at Fig. 3, the volume of traffic changes dynamically in short time periods, while the intensity during the day seems to be relatively equal. This indicates that actuated control could be a good solution for this junction.

\section{MODEL CREATION, CALIBRATION AND VALIDATION}

At the beginning, the model for the current traffic situation was created. In order to obtain the data outputs as similar to the outputs of calculations according to Slovak technical regulations as possible, 12 subpaths were created in the Aimsun model. Each subpath represents 1 traffic flow defined in TP102 (see Fig. 4).

\section{Calibration}

The model was calibrated on speed at the entrance A. The measured data for this calibration 
Table 1. Validation of the model on number of simulated vehicles.

\begin{tabular}{|c|c|c|c|c|c|}
\hline $\begin{array}{c}\text { Traffic flow/ } \\
\text { subpath }\end{array}$ & $\begin{array}{c}\text { Simulated } \\
\text { vehicles (veh) }\end{array}$ & $\begin{array}{c}\text { Standard deviation } \\
\text { (veh) }\end{array}$ & $\begin{array}{c}\text { Measured data } \\
\text { (veh) }\end{array}$ & $\begin{array}{c}\text { Difference } \\
\text { (veh) }\end{array}$ & Difference (\%) \\
\hline 1 & 17 & 4 & 17 & 0 & $0,00 \%$ \\
\hline 2 & 681 & 31 & 679 & 2 & $0,29 \%$ \\
\hline 3 & 38 & 3 & 37 & 1 & $2,70 \%$ \\
\hline 4 & 7 & 2 & 7 & 0 & $0,00 \%$ \\
\hline 5 & 39 & 6 & 38 & 1 & $2,63 \%$ \\
\hline 6 & 155 & 13 & 156 & -1 & $-0,64 \%$ \\
\hline 7 & 204 & 14 & 200 & 4 & $2,00 \%$ \\
\hline 8 & 549 & 19 & 554 & -5 & $-0,90 \%$ \\
\hline 9 & 78 & 11 & 76 & 2 & $2,63 \%$ \\
\hline 10 & 114 & 11 & 113 & 1 & $0,88 \%$ \\
\hline 11 & 59 & 7 & 56 & 3 & $5,36 \%$ \\
\hline 12 & 43 & 7 & 42 & 1 & $2,38 \%$ \\
\hline Sum & 1984 & & 1975 & 9 & $0,46 \%$ \\
\hline
\end{tabular}

\section{Model calibration}

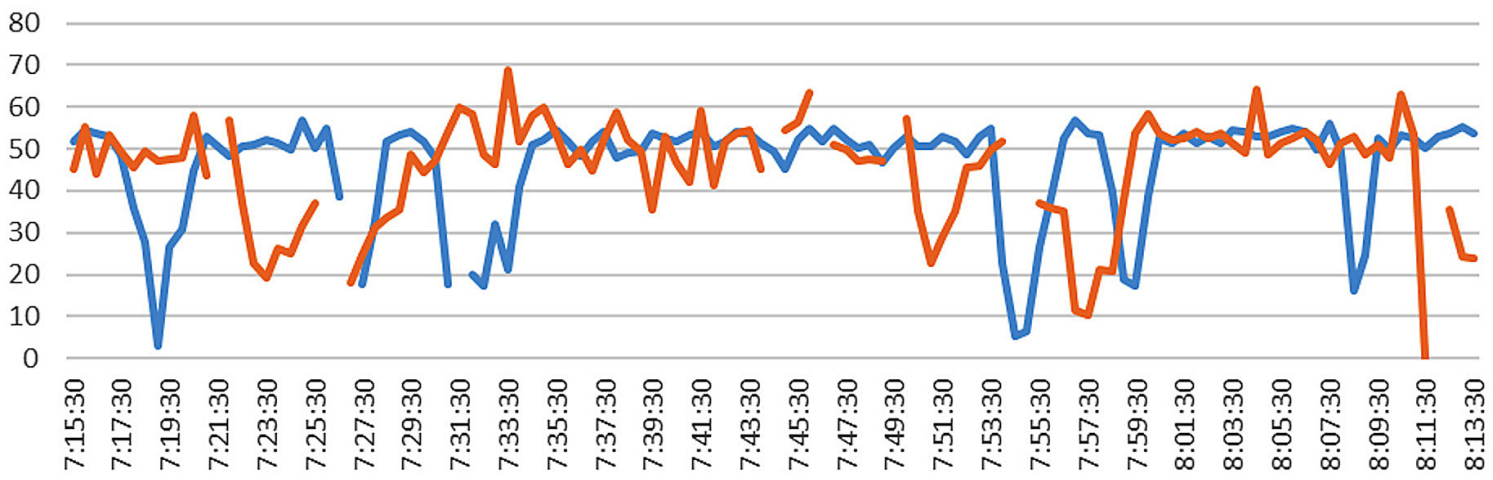

Fig. 5. Calibration of the model on speed at the entrance A

was obtained from the Sierzega SR4 device. (see fig 5). Average speed of the vehicles in the model was $46.08 \mathrm{~km} / \mathrm{h}$ and average speed of the vehicles counted by Sierzega was $45.54 \mathrm{~km} / \mathrm{h}$. The main reason why the speed decreased also to $0 \mathrm{~km} / \mathrm{h}$ is that vehicles coming from the main roads $(\operatorname{arm} \mathrm{A})$ needed to turn left to the arm D. In this case, the vehicles had to give way to the opposite vehicles (from arm B). The second reason is that these vehicles sometimes gave way to the vehicles becoming from side roads. Without this "friendly" giving way, it would be very hard to pass through the junction for the vehicles from side roads. In the Aimsun model, this behaviour of vehicles was achieved mainly by setting "Maximum Give Way Time". It can be seen that during 1 hour Aimsun gave this kind of priority 6 times and Sierzega showed that this occurred 4 times.

\section{Validation}

Validation was carried out by comparing the number of the simulated vehicles and measured vehicles. The maximum difference between the number of the measured and simulated is 5 (see Table 1.)

\section{TRAFFIC LIGHTS}

After calibration and validation of the traffic model for the current state, the model for traffic lights was created. The project of traffic lights designed some adjustments for this junction (see Fig. 6).

- Phase 1: min green: $21 \mathrm{sec}$, max green: 73 sec, extend detectors: D2 and D7, 

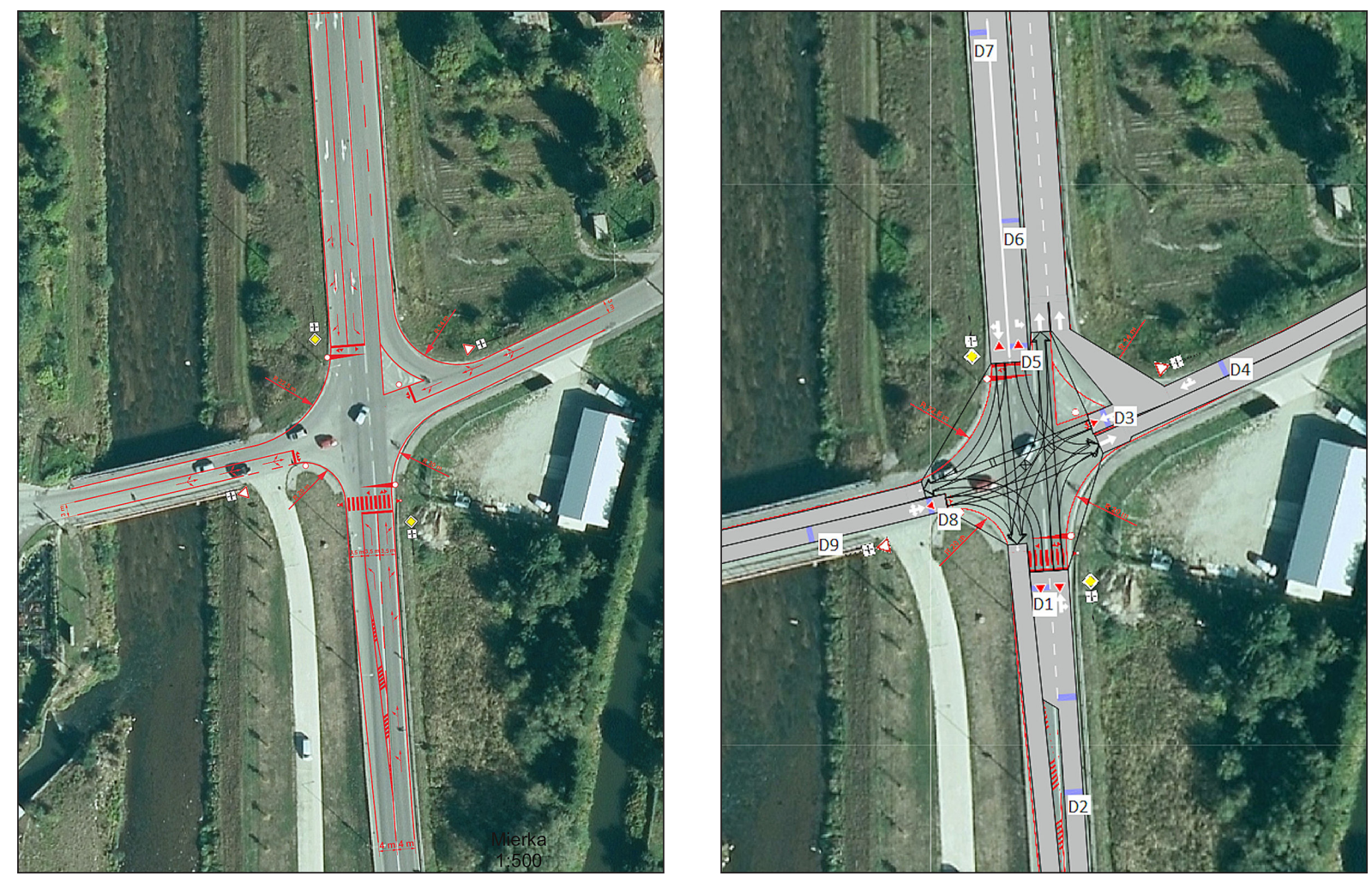

Fig. 6. The project of the traffic lights (on left) and traffic model of the traffic lights (on right)

- Phase 2: min green $8 \mathrm{sec}$, max green $18 \mathrm{sec}$, call detectors: D1 and D5, extend detector D6,

- Phase 3: min green $8 \mathrm{sec}$, max green $18 \mathrm{sec}$, call detectors: D3 and D8, extend detectors D4, D8 and D9,

- Phase 4: call detector - pedestrian calling, min green 8 , max. green 18 extend, extend detectors D4, D8 and D9.

Fixed control was designed according to technical regulations of the Slovak Republic TP102. The phases were designed as shown in Fig. 7.
For the morning peak the parameters were designed as follows: cycle length $80 \mathrm{sec}$, Phase 1: $42 \mathrm{sec}$, Phase 2: $14 \mathrm{sec}$, and Phase 3: $13 \mathrm{sec}$.

In turn, for the afternoon peak the designed parameters were: cycle length $60 \mathrm{sec}$, Phase 1: 31 sec, Phase 2: $9 \mathrm{sec}$, and Phase 3: $9 \mathrm{sec}$.

As it can be seen from the figures 4 on the left and figure 7, $\mathrm{K} 1$ is a combination of the subpaths 10,11 and $12, \mathrm{~K} 2$ is a combination of the subpaths 8 and 9, K3 is the subpath 7, K4 is a combination of the subpaths 4 and 5, K5 is a combination of the subpaths 2 and 3 and K6 is the subpath 1 .

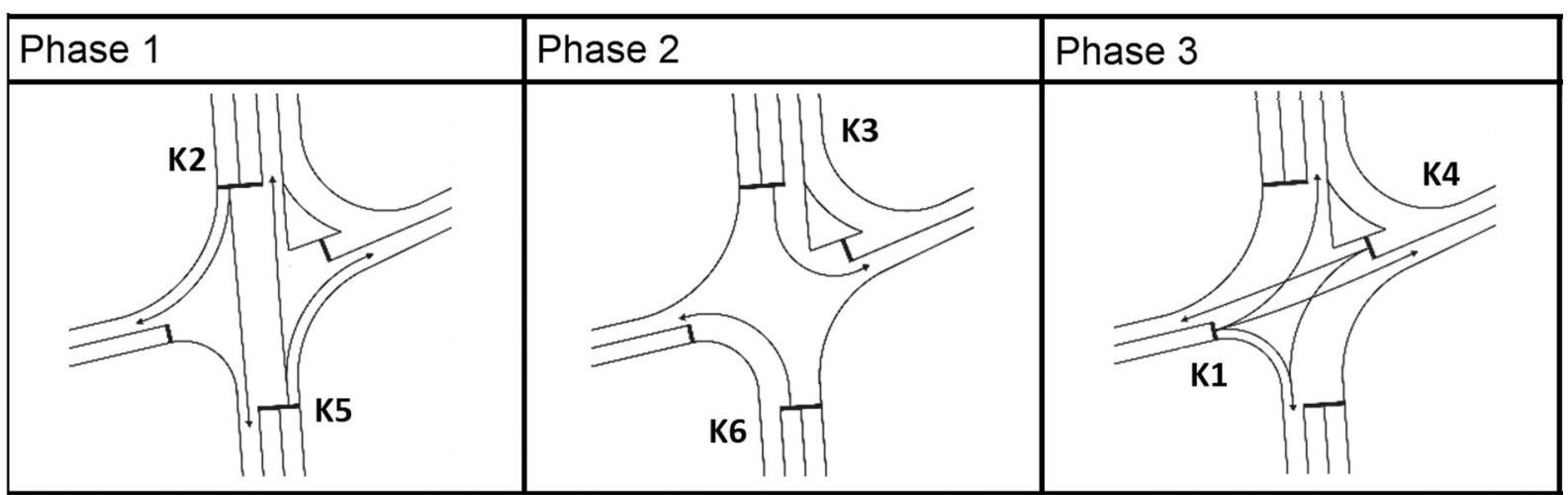

Fig. 7. Phases for the fixed traffic control 


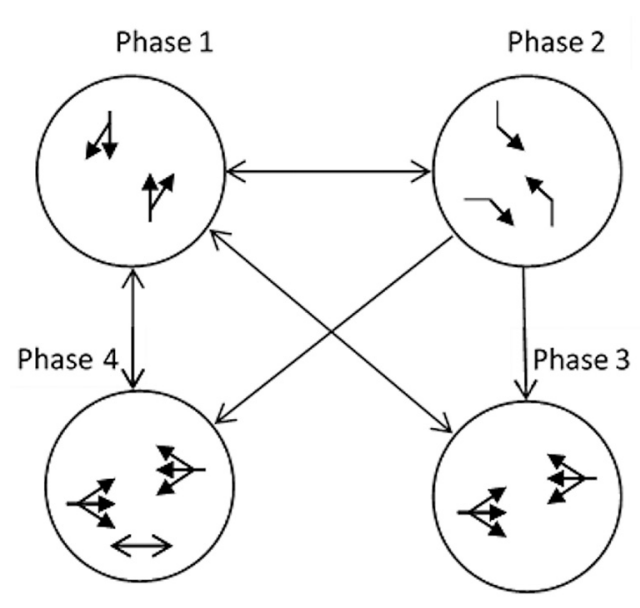

Fig. 8. Phases for the actuated control

Actuated control was designed for 4 phases, the difference between phase 3 and phase 4 is only green at pedestrian crossing (see Fig. 8).

\section{RESULTS}

\section{Simulation of the current traffic situation at this junction}

Simulation of the present state confirmed very high delays for the cars entering the junction from Bystrička (entrance $\mathrm{D}$, see Table 2). These delays can be up to 10 minutes $(601 \mathrm{sec})$ in the morning peak. Moreover, very high delays occur at the direction $\mathrm{C}-\mathrm{D}$ (from side road from Martin to side road to Bystrička), where average delay time is up to $116 \mathrm{sec}$. The situation is also very bad during afternoon peak. The delay times from Bystrička are shorter compared to morning peak, but still very long (up to $157 \mathrm{sec}$ at average).

With the help of microscopic modelling of current situation, it can be stated that the traffic exceeds the capacity of an uncontrolled junction.

\section{Simulation of the traffic lights with fixed control}

Simulation of the traffic lights with fixed control showed a significant decrease of the delay times of problematic junction entrances. The delay times from entrance D (from Bystrička) would be much shorter and would be, on average, up to 46 sec (present state $601 \mathrm{sec}$ ). Additionally, entrance C (side road from Martin) would have much shorter delay times (up to $36 \mathrm{sec}$, present state $116 \mathrm{sec}$ ). The only worsening compared to the present state is at the entrance A (delay times could increase by $9-13 \mathrm{sec})$. However, this can be considered as a common increase of the delay times, as the traffic flow with all priority will have also red light.

From these results it can be stated that the traffic lights with fixed control and designed adjustment of the junction could solve the bad traffic situation at the junction.

\section{Simulation of the traffic lights with actuated control}

As it was mentioned before, Martin prefers building traffic lights with actuated control to

Table 2. Microscopic simulation results. Delay times.

\begin{tabular}{|c|c|c|c|c|c|c|c|}
\hline \multirow[b]{2}{*}{ Entrance } & \multirow[b]{2}{*}{$\begin{array}{l}\text { Traffic } \\
\text { flow }\end{array}$} & \multicolumn{3}{|c|}{ Morning peak } & \multicolumn{3}{|c|}{ Afternoon peak } \\
\hline & & $\begin{array}{l}\text { Uncontrolled } \\
\text { Delay time } \\
\text { (sec) }\end{array}$ & $\begin{array}{l}\text { Fixed control } \\
\text { Delay time } \\
\text { (sec) }\end{array}$ & $\begin{array}{l}\text { Actuated control } \\
\text { Delay time (sec) }\end{array}$ & $\begin{array}{l}\text { Uncontrolled } \\
\text { Delay time } \\
\text { (sec) }\end{array}$ & $\begin{array}{c}\text { Fixed control } \\
\text { Delay time } \\
\text { (sec) }\end{array}$ & $\begin{array}{l}\text { Actuated control } \\
\text { Delay time (sec) }\end{array}$ \\
\hline \multirow{3}{*}{ A } & 1 & 29 & 37 & 41 & 10 & 28 & 34 \\
\hline & 2 & 9 & 24 & 21 & 2 & 16 & 16 \\
\hline & 3 & 9 & 22 & 20 & 2 & 15 & 15 \\
\hline \multirow{3}{*}{$\mathrm{C}$} & 4 & 82 & 43 & 36 & 52 & 29 & 32 \\
\hline & 5 & 116 & 34 & 31 & 66 & 26 & 26 \\
\hline & 6 & 26 & 6 & 5 & 9 & 3 & 3 \\
\hline \multirow{3}{*}{ B } & 7 & 96 & 46 & 41 & 37 & 52 & 34 \\
\hline & 8 & 84 & 21 & 18 & 29 & 16 & 16 \\
\hline & 9 & 34 & 20 & 17 & 6 & 16 & 15 \\
\hline \multirow{3}{*}{ D } & 10 & 582 & 46 & 35 & 137 & 36 & 29 \\
\hline & 11 & 601 & 44 & 32 & 157 & 33 & 26 \\
\hline & 12 & 567 & 40 & 28 & 134 & 31 & 23 \\
\hline
\end{tabular}



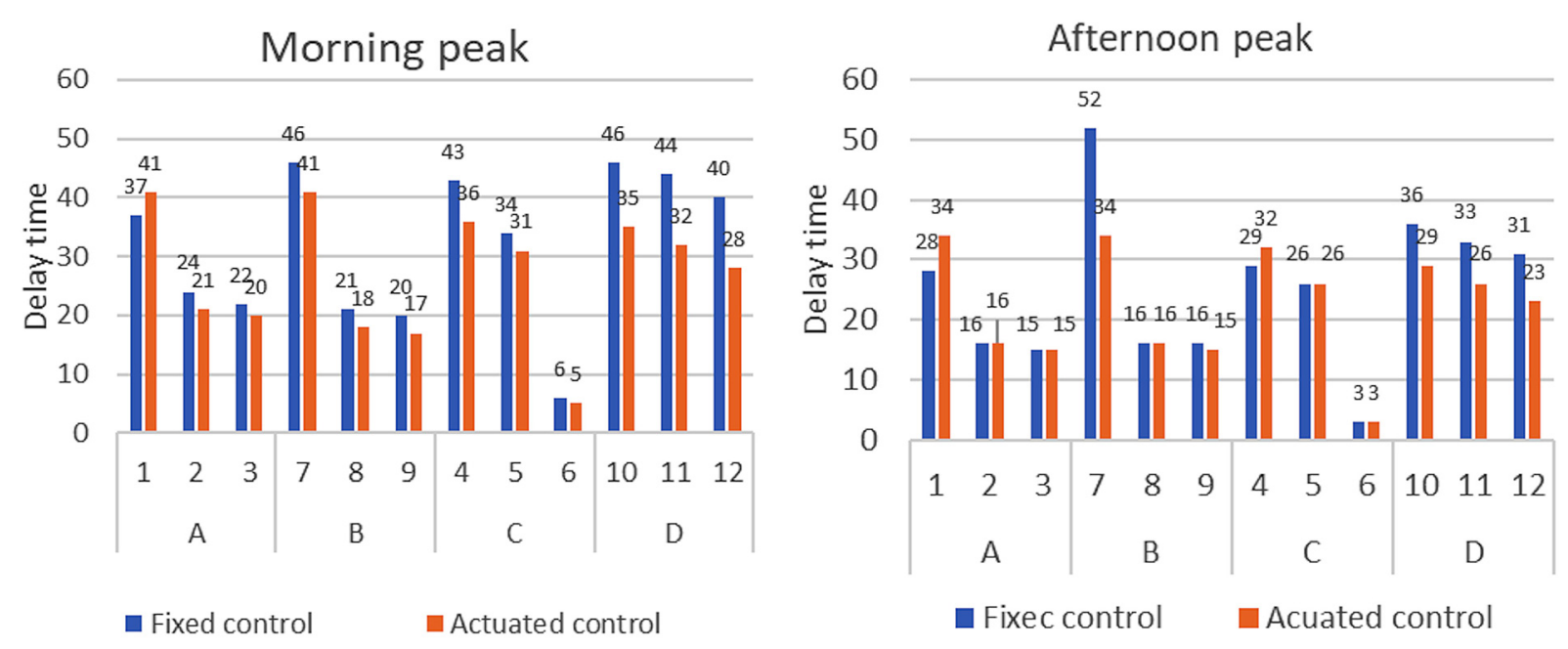

Fig. 9. Comparison of the fixed control and actuated control (morning peak on the left, afternoon peak on the right)

fixed control. Fig. 3 showed that traffic changes dynamically between every 5 minutes interval. This indicates that actuated control could be convenient for this junction.

Microscopic simulation showed that the designed actuated control at the junction can additionally decrease the delay times by $14 \%$ in the morning peak and by $12 \%$ in the afternoon peak (see Fig. 9 and Table 3). The most significant decreases can be noticed on side roads (up to $29 \%$ ). Traffic flow no. 01 indicates increasing of delay times when actuated control is used. A detailed look at microscopic simulations showed that this increase is caused by the vehicles waiting on red in row of vehicles of the traffic flow no. 02. As it can be seen in Fig. 6, traffic flow no. 1 has own lane for left turn to Bystrička, but this lane is not very long. When actuated control is used, phase 2 is only on call. Many vehicles waited in row during phase 1 and activated phase 2 (detector 1 ) in the time when phase 3 was in operation. Then they had to wait the rest of phase 3 and the whole phase 1 till phase 2 was activated. When fixed control was used, they did not have to wait this time.

\section{CONCLUSION}

Nearly every town has to face the problems which results from constantly increasing traffic. Properly designed traffic control at junction has a significant impact on traffic fluency. Smaller towns, up to 100000 of inhabitants, usually can solve these problems with simpler solutions such

Table 3. Decreasing of delay times with the help of actuated control for particular traffic flows.

\begin{tabular}{|c|c|c|c|}
\hline Entance & Traffic flow & Morning peak & Afternoon peak \\
\hline \multirow{4}{*}{$A$} & 01 & $11 \%$ & $20 \%$ \\
\cline { 2 - 4 } & 02 & $-10 \%$ & $1 \%$ \\
\cline { 2 - 4 } & 03 & $-10 \%$ & $-1 \%$ \\
\hline \multirow{4}{*}{$C$} & 04 & $-15 \%$ & $10 \%$ \\
\cline { 2 - 4 } & 05 & $-10 \%$ & $3 \%$ \\
\cline { 2 - 4 } & 06 & $-22 \%$ & $-4 \%$ \\
\hline \multirow{3}{*}{$B$} & 07 & $-12 \%$ & $-34 \%$ \\
\cline { 2 - 4 } & 08 & $-13 \%$ & $-3 \%$ \\
\cline { 2 - 4 } & 09 & $-14 \%$ & $-2 \%$ \\
\hline \multirow{3}{*}{$\mathrm{D}$} & 10 & $-25 \%$ & $-20 \%$ \\
\cline { 2 - 4 } & 11 & $-29 \%$ & $-25 \%$ \\
\cline { 2 - 4 } & 12 & $-14 \%$ & $-12 \%$ \\
\hline
\end{tabular}


as uncontrolled junctions, roundabouts or signal controlled junctions. When a signal controlled junction is needed, actuated traffic control usually gives better results compared to fixed control. This has been proven in various studies [7, $8,9]$ and this is also the case of the town of Martin. Microscopic simulation showed better results for actuated control compared to fixed control by $14 \%$ during morning peak and by $12 \%$ during afternoon peak. It is possible to assume that during low traffic, the results would be also in favour of actuated control.

\section{Acknowledgement}

This work was supported in part by the Grant VEGA no. 1/0436/18 - Externalities in road transport, an origin, causes and economic impacts of transport measures.

\section{REFERENCES}

1. Kalasova A., Kupculjakova J., Kubikova S. and Palo J. Traffic Time Delay Modelling on the Intersection in the City of Martin, Using Software Aimsun. Proc. of 14th Scientific and Technical Conference on Transport Systems - Theory and Practice (TSTP), 2018, 203-2012.

2. Gogola M., Hocova M. Deurbanisation and mobility. Proc. Of 6th Transport Research Arena. Warsaw, Poland 2016, 1193-1200.

3. Gavulova A. and Drliciak M. Capacity Evaluation of Roundabouts in Slovakia. Transport and Telecommunication Journal. 13(1), Poland 2012, 1-10.

4. Lizbetin J. and Stopka O. Proposal of a Roundabout Solution within a Particular Traffic Operation. Open Engineering, 6(1), 2016, 441-445.

5. Mateen A., Sher S., Rehman A., Hanif Z., Akhtar T. and Ashraf M. Dynamic Traffic Control and Management System for Smart Cities. Advances in Science and Technology Research Journal. 12(4), 2018, 2016-225.

6. Culik K., Harantova V., Kalasova A. Traffic Modelling of the Circular Junction in the City of Zilina.
Advances in Science and Technology Research Journal. 13(4), 2019, 162-169.

7. Pribyl P and Mach R. Ridící systémy silniční dopravy. Praha: Vydavatelství ČVUT, 2003.

8. Moganarangan N., Balaji N., Suresh Kumar R.G., Balaji S. and Palanivel N. Study on Static and Dynamic Traffic Control Systems. International Journal of Pure and Applied Mathematics 119(12), 2018, 565-579.

9. Taher F., El-Sayed A., Shouman A. and El-Mahalawy A. Comparing Different Techniques for Controlling Traffic Signals. International Journal on Power Engineering and Energy. 7(3), 2016, 680-686i.

10. Birr K., Jamroz K., Kustra W. Travel Time of Public Transport Vehicles Estimation. 17th meeting of the Euro Working Group on Transportation, EWGT2014, 2014, 359-365.

11. Skrucany T., Kendra M., Stopka O., Milojevic S., Figlus T. and Csiszar C. Impact of the Electric Mobility Implementation on the Greenhouse Gases Production in Central European Countries. Sustainability, 11(18), 2019, Article Number 4948.

12. Sarkan B., Semanova S., Harantova V., Stopka O., Chovancova M. and Szala M. Vehicle fuel consumption prediction based on the data record obtained from an engine control unit. 3rd International Conference of Computational Methods in Engineering Science (CMES 18), Volume 252, 2019, Article Number 06009.

13. Ondrus J. and Karon G., Video System as a Psychological Aspect of Traffic Safety Increase. 17 th International Conference on Transport Systems Telematics (TST), Katowice, Poland 2017, 167-177.

14. Ministry of Transport and Construction of the Slovak Republic: Technical Conditions 102, Calculation of Road Communications Capacity. Ministry of Transport and Construction of the Slovak Republic,Slovak Republic, 2015.

15. Korfant M. and Gogola M. Possibilities of using traffic planning software in Bratislava. 12th International Scientific Conference of Young Scientists on Sustainable, Modern and Safe Transport, Volume 192, 2017, 433-438.

16. Schlosser T. and Schlosser P. Traffic Engineering Analysis in the Preparation and Reconstruction of Urban Roads. Slovak Journal of Civil Engineering. 26(2), 2018, 35-39. 